\title{
Survivorship - Food for thought: Systematic review of Cancer Survivors Perceptions of Food Related Information
}

Review Article

Canham, R ${ }^{1,2}$, Shaw, R.L 2* $^{*}$

${ }^{1}$ Senior Consultant, Greenstreet Berman Ltd, London, UK.

${ }^{2}$ School of Life and Health Sciences, Aston University Birmingham B4 7ET, UK.

\section{Abstract}

During 2011, 331,487 new cases of cancer were diagnosed within the UK. Within the same year, cancer survival rates were reported to be approximately $50 \%$, with those diagnosed said to live, on average, 10 more years following diagnosis. Cancer patients are considered 'at risk' of food borne illness, in particular, from Listeria Monocytogenes. Whilst common, Listeria can prove fatal to cancer patients who may be immune suppressed. Appropriate food safety and nutritional advice is therefore important to ensuring the health and continued recovery of cancer sufferers during the stages of diagnosis and treatment, but also through to survival and transition back into 'normal' life.

This Mixed Studies Review (MSR) therefore sought to better understand Cancer survivors' perceptions of food related information, with a view to enhancing the effectiveness of such information in future. The findings revealed a preference for receiving more information as opposed to less, with survivors primarily seeking relevant and prescriptive guidance via practitioners and paper based channels. Food related information was also valued when provided as part of broader lifestyle advice.

Theoretical implications are discussed and recommendations for theory and practice are presented, however, the few studies identified by this review provide little evidence on which to base definitive decisions for future practice, in particular with regards to food safety messages. Further research in this area is therefore required.

Key words: Food Safety; Nutrition; Information Dissemination; Education; Consumer Health Information; Cancer Survivors.

\section{Introduction \& Rationale}

\section{Cancer survivorship within the UK}

According to Cancer Research UK [1], there were 331,487 new cases of cancer diagnosed in the UK during 2011. Within the same timeframe, CRUK also reported a survival rate of approximately $50 \%$, with those diagnosed living a further 10 more years. Two of the most common types are cancer of the breast and bowel, with 50,285 and 41,581 cases recorded respectively within 2011 [2]. Of these cases, survival rates are strong and continue to rise, with an estimated two in three women diagnosed with breast cancer surviving in excess of 20 years and approximately 6-10 bowel cancer diagnoses surviving in excess of 10 years.
These figures demonstrate the need to focus intervention and support beyond the stages of diagnosis and treatment, but through to survival and transition back into 'normal' life. For many survivors, the advice and support provided to help manage the physical, psychological and emotional experiences following treatment is variable. Knowing how to find useful and reliable information can help increase confidence, quality of life and long term recovery [3].

\section{Vulnerability to food borne illness}

Cancer patients have been identified as a vulnerable group, considered 'at risk' of Listeria Monocytogenes, a common and severe food borne pathogen [4, 5]. Once contracted Listeria Monocytogenes can prove fatal to cancer patients who may be resistant to

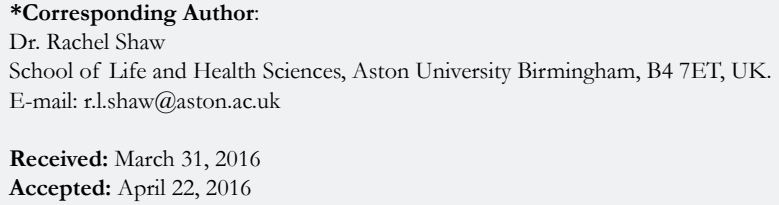

Copyright: Shaw $\mathbf{R L}^{\circ}$ 2016. This is an open-access article distributed under the terms of the Creative Commons Attribution License, which permits unrestricted use, distribution and reproduction in any medium, provided the original author and source are credited. 
antibiotics, as tumour cells genetically resist cytostatic drugs [6].

Qualitative research with cancer patients has previously revealed discrepancies between risk awareness, susceptibility and mitigating behaviours. Despite acknowledging their enhanced vulnerability to food borne illness, patients did not link this vulnerability to food handling or consumption behaviours, with many reporting consumption of foods considered to be of high risk of lysteriosis, such as eggs with runny yolks or cured meats [7]. In some instances, patients lacked awareness of food considered to be 'high risk' when immune compromised [8].

In a review of consumer food safety practices commissioned by the Food Standards Agency [4] the following recommendations were proposed to manage the increased risk of Listeria Monocytogenes amongst cancer patients:

- Development of targeted dietary advice, if possible in collaboration with the professionals that care for cancer patients, such as oncologists, dieticians, oncology centres and chemotherapy units;

- Advice be communicated to patients by those healthcare professionals; and

- Work should involve specialist organisations, such as the Oncology Section of the Royal Society of Medicine and the NHS Cancer Programme.

\section{Review Aims}

The objective of this Mixed Studies Review (MSR) was to better understand Cancer survivors' perceptions of food related information, with a view to enhancing the effectiveness of such information in future. The study method comprised four key stages: a) Systematic search; b) critical appraisal of studies; c) Constant comparison of the data; and d) Interpretative thematic analysis. The following research questions were proposed to guide the review:

1. How do Cancer survivors perceive the food related information they receive? In particular:

- the delivery mechanism/channel used to communicate the information;

- relevance of content; and

- $\quad$ understanding of the message.

2. Which sources of food related information are used and trusted amongst cancer survivors?

3. What content is covered within the food related information provided to cancer survivors?

- Does the information cover both dietary advice and food safety recommendations?

Figure 1. SPIDER search terms and scope

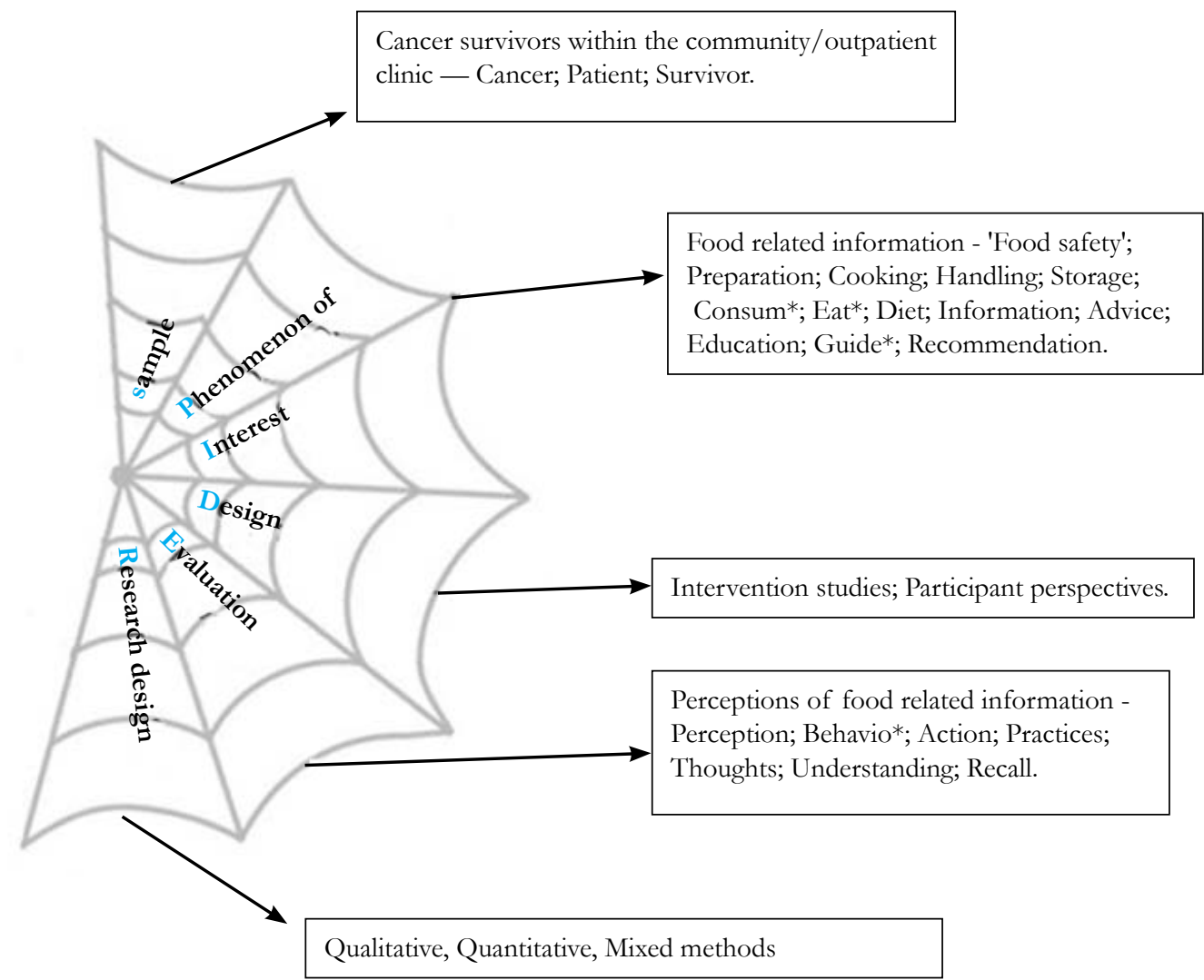


Figure 2. PRISMA flowchart of search and screening output.
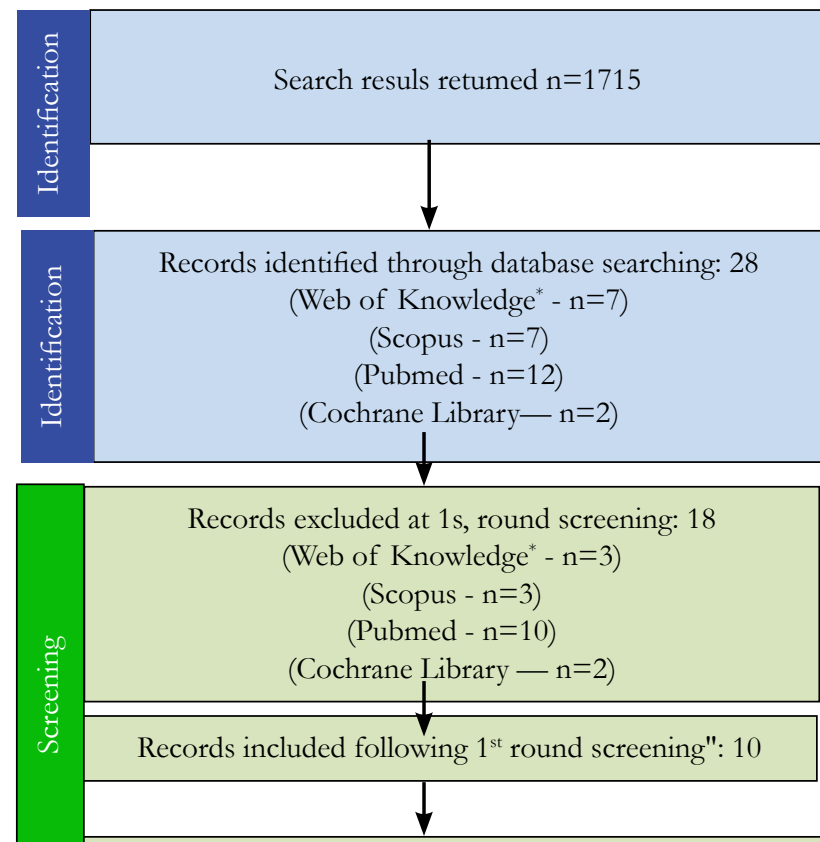

Records included following $2^{\text {nd }}$ round screening ${ }^{* * *}: 10$
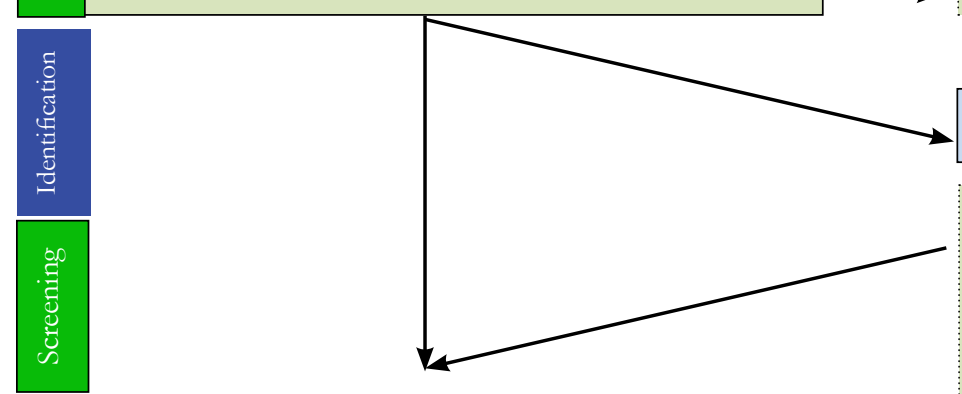

Records included following $3^{\text {rd }}$ round screening ${ }^{* * *}: 11$

Qualitative studies $(n=3)$

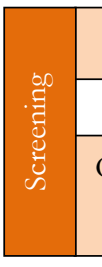

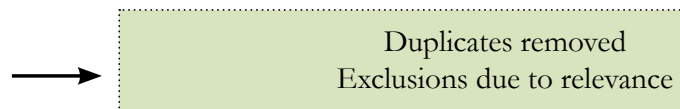

Reasons for exclusion at $1^{\text {st }}$ round screening:

Duplicates $(n=5)$

Not concerned with food related info $(n=4)$

Not concerned with perceptions of info $(n=5)$

Target sample $(n=3)$

Unable to obtain $\operatorname{paper}(\mathrm{n}=1)$

Additional records identified through reference chaining: 17

Reasons for exclusion following $3^{\text {rd }}$ round screening: Duplicates $(\mathrm{n}=3)$

Not concerned with food related info $(\mathrm{n}=5)$

Not concerned with perceptions of info $(\mathrm{n}=5)$

Target sample $(n=3)$

No records were excluded at $2^{\text {nd }}$ round screening.

1 Taken from Maher, D., Liberati, A, Tetilaff, J., A kman, D.G., The PRISMA Group (2009). Preferred Reporting items for Systematic Reviews and Meta-Analyses: The PRISMA Statement. PLoS Med 6(6): e1000097. doi: 10.13711joumal.pmed1000097. Available at http://www.prisma-statementorg (accessed 29 Jan. 10).

* Web of knowledge search incorporated Web of Science, MEDLINE, BIOSIS Citation IndexSM

** Screened on the basis of title and abstract

*** Screened using the full text

**** Screened using title, abstract and ful text

4. What theoretical models and interventions have been applied to improve nutritional intake and safe food handling practices amongst cancer survivors?

It was beyond the scope of this research to evaluate the success of the various methods/interventions with regards to their impact on health behaviours and outcome measures taken.

\section{Method}

The present MSR incorporated qualitative, quantitative and mixed methods studies.

\section{Systematic search}

The SPIDER (Sample, Phenomenon of Interest, Design, Evaluation and Research type, as illustrated in Figure 1, adapted from [9]) tool enabled selection and refinement of search terms.

A systematic search was conducted within Web of Knowledge, Scopus, PubMed and the Cochrane database of systematic reviews. The search terms outlined in Table 1 were combined using Boolean logic ('and' and 'or') and wildcards within each database.

\section{Screening}

Defined inclusion criteria (presented within Table 2) were used 
Figure 3. Interpretative thematic analysis themes generated.

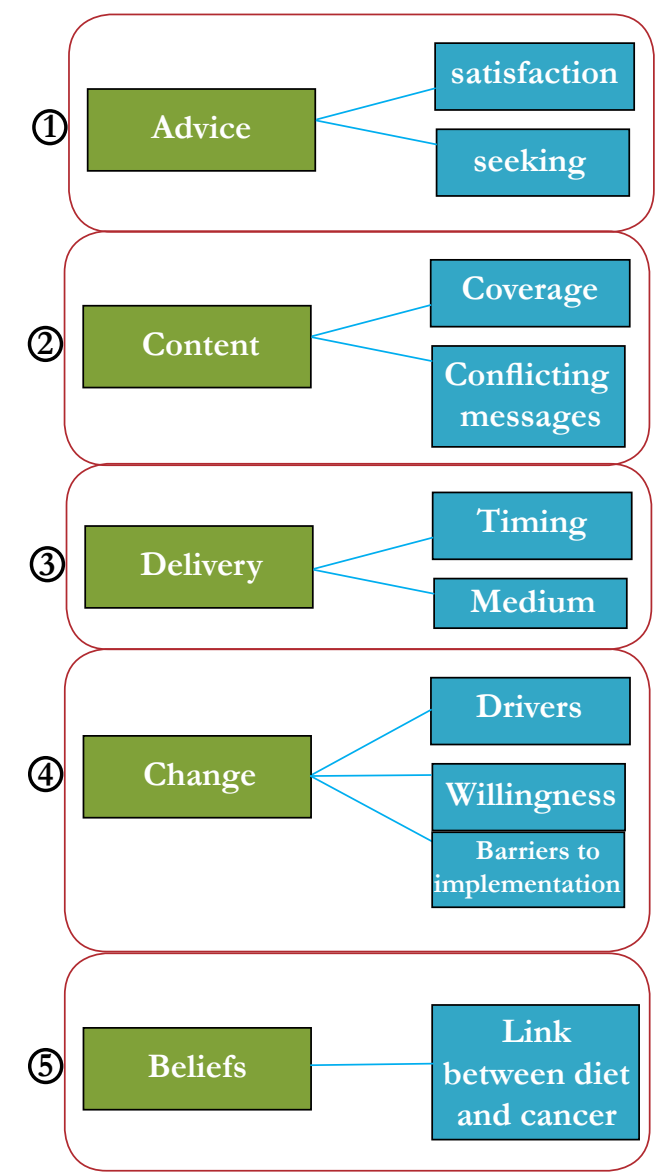

Table 1. Search terms and syntax used.

\begin{tabular}{|c|c|c|c|}
\hline A. Words related to 'cancer'. & B. Words related to 'food' & C. Words related to 'behaviour' & $\begin{array}{c}\text { D. Words related to 'Informa- } \\
\text { tion' }\end{array}$ \\
\hline Cancer & 'Food safety' & Action & Information \\
\hline Patient* & Preparation & Practices & Pdvice \\
\hline Sufferer & Cooking & Thoughts & Education \\
\hline Survivor & Handling & Understanding & Ruide* \\
\hline 'At risk' & Storage & Recall & \\
\hline
\end{tabular}

Table 2. inclusion/exclusion search criteria.

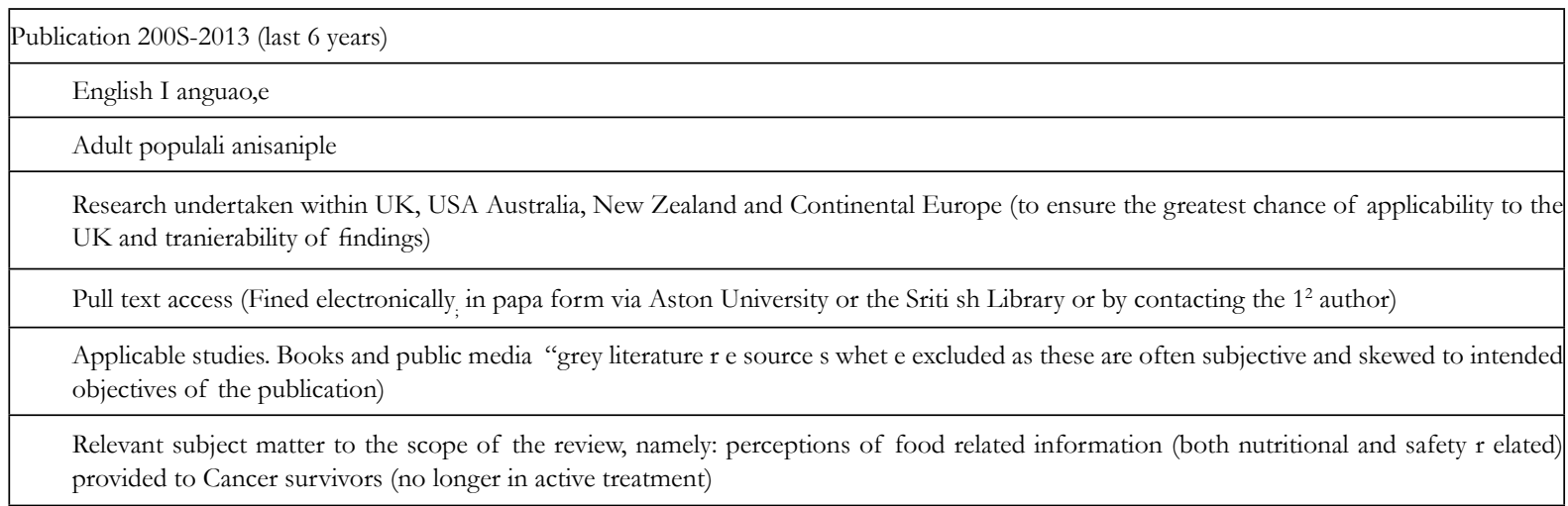


Table 3. Study characteristics and quality appraisal scores for included papers.

\begin{tabular}{|c|c|c|c|c|c|c|c|}
\hline Study & Country & Aims & Participants & Type of cancer & $\begin{array}{l}\text { Data collection } \\
\text { method }\end{array}$ & $\begin{array}{c}\text { Data analysis } \\
\text { method }\end{array}$ & $\begin{array}{l}\text { Quality ap- } \\
\text { praisal score }\end{array}$ \\
\hline Pullar et al (2012) & New Zealand & $\begin{array}{c}\text { Identify the dietary patterns of } \\
\text { CRC patients, level of dietary } \\
\text { advice received and its impact on } \\
\text { behaviour. }\end{array}$ & $\begin{array}{c}\mathrm{n}=40 \\
21(53 \%) \text { Male } \\
19(47 \%) \text { Female } \\
\text { Age } 40+\end{array}$ & Colorectal Cancer & Survey & $\begin{array}{l}\text { Quantitative } \\
\text { descriptive }\end{array}$ & $25 \%$ \\
\hline Urowitz et al (2012) & Canada & $\begin{array}{c}\text { Test the feasibility of registered } \\
\text { dieticians, professional chefs } \\
\text { and food scientists developing } \\
\text { recipes to support healthy eating } \\
\text { amongst Cancer survivors;Test } \\
\text { whether cooking demonstrations } \\
\text { supported by educational studies } \\
\text { would help to improve the eating } \\
\text { habits of Cancer survivors. }\end{array}$ & $\begin{array}{c}\mathrm{n}=18 \\
5(28 \%) \text { Male } \\
13(72 \%) \text { Female } \\
\text { Age unknown }\end{array}$ & Colorectal Cancer & $\begin{array}{l}\text { Questionnaire } \\
\text { and survey }\end{array}$ & Mixed Methods & $0 \%$ \\
\hline Lawler et al (2011) & Australia & $\begin{array}{c}\text { Examine patient experiences and } \\
\text { perceptions of follow up care } \\
\text { after active treatment for breast } \\
\text { cancer. }\end{array}$ & $\begin{array}{c}\mathrm{n}=25 \\
25(100 \%) \text { Female } \\
\text { Age } 35-69\end{array}$ & Breast Cancer & $\begin{array}{l}\text { Telephone } \\
\text { interviews and } \\
\text { questionnaire }\end{array}$ & Qualitative & $75 \%$ \\
\hline Mroz et al (2010) & Canada & $\begin{array}{c}\text { Explore men's perceptions of } \\
\text { their diets following diagnosis; } \\
\text { Rationales underpinning dietary } \\
\text { change. }\end{array}$ & $\begin{array}{c}\mathrm{n}=14 \\
14(100 \%) \text { Male } \\
\text { Age } 47-78\end{array}$ & Prostate Cancer & $\begin{array}{l}\text { Interviews and } \\
\text { food journals }\end{array}$ & Qualitative & $100 \%$ \\
\hline $\begin{array}{l}\text { Anderson, Steele } \\
\text { and Coyle (2013) }\end{array}$ & $\mathrm{UK}$ & $\begin{array}{l}\text { Explore perceived patient needs } \\
\text { for advice on diet, activity and } \\
\text { beliefs about the role of lifestyle } \\
\text { for reducing disease recurrence. }\end{array}$ & $\begin{array}{c}\mathrm{n}=40 \\
20(50 \%) \text { Male } \\
20(50 \%) \text { Female } \\
\text { Age } 27-84\end{array}$ & Colorectal Cancer & Focus groups & Qualitative & $50 / 75 \%$ \\
\hline Garrett et al (2013) & USA & $\begin{array}{l}\text { Feasibility study of a telephone } \\
\text { counselling program to enhance } \\
\text { psychosocial and physical well- } \\
\text { being for Cancer survivors. }\end{array}$ & $\begin{array}{c}\mathrm{n}=66 \\
22(48 \%) \text { Male } \\
24(52 \%) \text { Female } \\
\text { Age } 20+\end{array}$ & Unknown & Questionnaire & $\begin{array}{l}\text { Quantitative } \\
\text { descriptive }\end{array}$ & $75 \%$ \\
\hline Tan et al (2012) & USA & $\begin{array}{l}\text { Explore Cancer survivor's en- } \\
\text { gagement with diet information } \\
\text { provided by a range of sources. } \\
\text { Examine whether engage- } \\
\text { ment with these sources affects } \\
\text { behaviour }\end{array}$ & $\begin{array}{c}\mathrm{n}=1128 \\
541(48 \%) \text { Male } \\
587(52 \%) \text { Female } \\
\text { Mean age } 68\end{array}$ & $\begin{array}{c}\text { Colorectal, breast } \\
\text { and prostate } \\
\text { Cancer }\end{array}$ & $\begin{array}{c}\text { Survey (longitu- } \\
\text { dinal) }\end{array}$ & $\begin{array}{l}\text { Quantitative } \\
\text { descriptive }\end{array}$ & $75 \%$ \\
\hline Stead et al (2012) & UK & $\begin{array}{c}\text { Explore whether adenoma diag- } \\
\text { nosis might present a 'teachable } \\
\text { moment'; } \\
\text { Explore feelings surrounding } \\
\text { diagnosis, understanding of } \\
\text { significance and the extent the } \\
\text { experience motivates behaviour } \\
\text { change. }\end{array}$ & $\begin{array}{c}\mathrm{n}=17 \\
12(71 \%) \text { Male } \\
5(29 \%) \text { Female } \\
\text { Age } 50-74\end{array}$ & Colorectal Cancer & Focus groups & Qualitative & $75 \%$ \\
\hline Hawkes et al (2009) & Australia & $\begin{array}{c}\text { Feasibility and short-term effec- } \\
\text { tiveness of a lifestyle intervention } \\
\text { for cancer survivors. }\end{array}$ & $\begin{array}{c}\mathrm{n}=20 \\
10(50 \%) \text { Male } \\
10(50 \%) \text { Female } \\
\text { Median age } 66\end{array}$ & Colorectal Cancer & $\begin{array}{l}\text { Telephone } \\
\text { interview }\end{array}$ & Mixed methods & $75 / 50 \%$ \\
\hline $\begin{array}{l}\text { Medeiros et al } \\
\qquad(2008)\end{array}$ & USA & $\begin{array}{l}\text { Asses the food safety information } \\
\text { needs of cancer patients; } \\
\text { Determine factors affecting edu- } \\
\text { cational interventions that foster } \\
\text { risk reducing behaviours }\end{array}$ & $\begin{array}{c}\mathrm{n}=31 \\
\text { "\% Male/female } \\
\text { unknown } \\
\text { Age unknown" }\end{array}$ & Unknown & $\begin{array}{l}\text { Focus groups } \\
\text { and interviews }\end{array}$ & Mixed methods & $75 \%$ \\
\hline $\begin{array}{l}\text { Anderson et al } \\
\quad(2010)\end{array}$ & Scotland & $\begin{array}{c}\text { Test the feasibility and acceptabil- } \\
\text { ity of a 3-month intervention to } \\
\text { inform the design of an RCT. } \\
\text { Inform understanding of how } \\
\text { colorectal cancer survivors } \\
\text { respond to lifestyle interventions, } \\
\text { acceptability of a range of assess- } \\
\text { ment measures and implications } \\
\text { for study design and power } \\
\text { calculations. }\end{array}$ & $\begin{array}{c}\mathrm{n}=18 \\
16(90 \%) \text { Male } \\
2(10 \%) \text { Female } \\
\text { Mean age } 61\end{array}$ & Colorectal Cancer & \begin{tabular}{|c|} 
In depth \\
interviews, \\
questionnaires, \\
participant \\
diaries, accel- \\
erometers and \\
anthropometric \\
measures (e.g. \\
waist measure- \\
ment).
\end{tabular} & Mixed methods & $25 \%$ \\
\hline
\end{tabular}


Table 4. Complete record of themes identified and generated during synthesis.

\begin{tabular}{|c|c|c|c|c|}
\hline $\begin{array}{c}3^{\text {rd }} \text { order constructs } \\
\text { (themes) }\end{array}$ & Sub themes & Papers & $2^{\text {nd }}$ order constructs & $1^{\text {st }}$ order constructs \\
\hline \multirow[b]{2}{*}{ Advice } & Satisfaction & $\begin{array}{c}\text { Pullar et al } 2012 \\
\text { Medeiros et al,2008 } \\
\text { Hawkes et al,2009 }\end{array}$ & $\begin{array}{c}\text { No patients felt they had received too much dietary } \\
\text { information, whereas } 61 \% \text { felt they had received too } \\
\text { little or far too little. (Pullar et al (2012)) }\end{array}$ & No $1^{\text {st }}$ order construct presented. \\
\hline & Seeking & $\begin{array}{l}\text { Lawler et al, } 2011 \\
\text { Anderson, Steele } \\
\text { and Coyle,2013 } \\
\text { Tan et al,2012 }\end{array}$ & $\begin{array}{l}\text { Some women perceived a need for other types of } \\
\text { health professionals to be involved in their follow up } \\
\text { care, such as dieticians and physiotherapists to assist } \\
\text { with making lifestyle changes (diet, exercise, comple- } \\
\text { mentary or alternative medicine) addressing other } \\
\text { health issues (e.g. Lymphodema) and improving mo- } \\
\text { tion all wellbeing. (Lawler et al, 2011) }\end{array}$ & $\begin{array}{l}\text { "I had to ask to see a dietician cause I had put on a } \\
\text { lot of weight. Um, and that was concerning me and } \\
\text { causing me stress... But that was all instigated by me" } \\
\text { (Lawler et al, 2011) }\end{array}$ \\
\hline \multirow{2}{*}{ Content } & Coverage & \begin{tabular}{|c|} 
Pullar et al 2012 \\
Medeiros et al,2008
\end{tabular} & $\begin{array}{c}\text { For the participants who received dietary advice dur- } \\
\text { ing treatment, } 50 \% \text { received advice relating specifi- } \\
\text { cally to their treatment (e.g. stoma advice, weight gain } \\
\text { advice or advice for overcoming a low appetite), the } \\
\text { other } 50 \% \text { received advice specific to CRC survivor- } \\
\text { ship (e.g. reducing and avoiding red/processed meat } \\
\text { and increasing fruits and vegetables). (Pullar et al } \\
\text { 2012) }\end{array}$ & No $1^{\text {st }}$ order construct presented. \\
\hline & $\begin{array}{l}\text { Conflicting } \\
\text { messages }\end{array}$ & \begin{tabular}{|} 
Anderson, Steele \\
and Coyle,2013 \\
Stead et al,2012 \\
Medeiros et al,2008
\end{tabular} & $\begin{array}{l}\text { Indeed, some participants reported that practitioners } \\
\text { had turned orthodox medical advice on healthy eating } \\
\text { 'on its } \\
\text { head' after surgery by recommending fatty junk food; } \\
\text { this caused confusion and anxiety among patients. } \\
\text { (Anderson, Steele and Coyle,2013) }\end{array}$ & $\begin{array}{l}\text { "I mean prior to surgery it's low sugar, no salt, fat } \\
\text { free, all the rest of it, and then suddenly after sur- } \\
\text { gery it was no, no, you must eat to get your strength } \\
\text { back again and build up your weight again, you must } \\
\text { reverse all that and drink full fat milk and } \\
\text { take plenty of salt,[...] I found that quite difficult." } \\
\text { (Anderson, Steele \& Coyle, 2013) }\end{array}$ \\
\hline \multirow{2}{*}{ Delivery } & Timing & $\begin{array}{l}\text { Stead et al,2012 } \\
\text { Anderson, Steele } \\
\text { and Coyle,2013 }\end{array}$ & \begin{tabular}{|} 
Some participants expressed the need for a holistic \\
package of care which included assessment and advice \\
on diet, exercise, lifestyle and emotions in both the \\
short and long term (post 6 months). (Anderson, \\
Steele and Coyle,2013)
\end{tabular} & $\begin{array}{l}\text { "Personally what I would like to see at the end of } \\
\text { treatment, some sort of survivorship audit where } \\
\text { they're looking at your diet, your lifestyle, how } \\
\text { much exercise you're getting, ... and also the other } \\
\text { aspects which doesn't really get enough recognition } \\
\text { is stress and anxiety is as much a side effect of your } \\
\text { treatment as diarrhoea and neuropathy. I would like } \\
\text { to see a package of those things at the end." (Ander- } \\
\text { son, Steele \& Coyle, 2013) }\end{array}$ \\
\hline & Medium & $\begin{array}{c}\text { Pullar et al 2012 } \\
\text { Urowitz et al,2012 } \\
\text { Anderson, Steele } \\
\text { and Coyle,2013 } \\
\text { Garrett et al } \\
\text { (2013) } \\
\text { Tan et al,2012 } \\
\text { Medeiros et al,2008 }\end{array}$ & \begin{tabular}{|}
...many participants felt that being able to talk to \\
'expert patients' (patients who had experienced all the \\
treatment and were survivors) was most helpful. Such \\
'expert patients' could tell them what to expect in \\
terms of mobility, pain, recovery and what was 'nor- \\
mal' in terms of physiological signs and symptoms. \\
Support groups were therefore seen as supportive and \\
informative and able to allay fears and be reassuring. \\
(Anderson, Steele \& Coyle, 2013)
\end{tabular} & $\begin{array}{l}\text { "[The thing] I found most useful was actually when } \\
\text { I started coming to the bowel group in here...I think } \\
\text { I was maybe due to get my stoma reversal and there } \\
\text { was two people just had the reversal and they talked } \\
\text { through it, I learned more from that than going on } \\
\text { any internet or even speaking with the colorectal } \\
\text { specialists." (Anderson, Steele \& Coyle, 2013) }\end{array}$ \\
\hline \multirow{3}{*}{ Change } & Drivers & \begin{tabular}{|} 
Pullar et al 2012 \\
Urowitz et al,2012 \\
Anderson, Steele \\
and Coyle,2013 \\
Garrett et al \\
(2013)
\end{tabular} & $\begin{array}{l}\text { Participants had two distinct types of self-manage- } \\
\text { ment goals_-one involved 'returning' to their previous } \\
\text { 'selves' and the other concerned a 'renewal' of the self. } \\
\text { If the person felt they had a healthy active lifestyle and } \\
\text { they were happy with their body and weight before the } \\
\text { onset of illness, their aim is to return to that lifestyle } \\
\text { and bodily appearance. (Anderson, Steele \& Coyle, } \\
\text { 2013) }\end{array}$ & $\begin{array}{l}\text { "I think we're really all trying to get back to where } \\
\text { we were... That for me was the challenge [...] to get } \\
\text { back to where I was before this all started" (Ander- } \\
\text { son, Steele \& Coyle, 2013) }\end{array}$ \\
\hline & Willingness & $\begin{array}{c}\text { Pullar et al } 2012 \\
\text { Urowitz et al,2012 } \\
\text { Tan et al,2012 } \\
\text { Anderson et } \\
\text { al,2010) }\end{array}$ & $\begin{array}{l}\text { Only } 5 \% \text { of participants would not consider making } \\
\text { dietary changes based on additional dietary advice, } \\
\text { while } 75 \% \text { would consider making changes. Around } \\
20 \% \text { reported they were 'unsure' as to whether they } \\
\text { would consider making dietary changes based on ad- } \\
\text { ditional advice. (Pullar et al } 2012 \text { ) }\end{array}$ & No $1^{\text {st }}$ order construct presented. \\
\hline & $\begin{array}{l}\text { Barriers to im- } \\
\text { plementation }\end{array}$ & $\begin{array}{c}\text { Stead et al,2012 } \\
\text { Medeiros et al,2008 }\end{array}$ & $\begin{array}{l}\text {...people said they did not use a thermometer for } \\
\text { ground mean and chicken breasts or did not own } \\
\text { a food thermometer. The majority of participants } \\
\text { preferred to use visual techniques for doneness when } \\
\text { cooking meat. (Medeiros } \text { et al,2008) }\end{array}$ & $\begin{array}{l}\text { "I have cooked long enough to know what is done } \\
\text { or not" (Medeiros et al, 2008) }\end{array}$ \\
\hline
\end{tabular}




\begin{tabular}{|c|c|c|c|c|}
\hline Beliefs & $\begin{array}{l}\text { Link between } \\
\text { diet \& Cancer }\end{array}$ & $\begin{array}{c}\text { Mróz, et al,2010 } \\
\text { Anderson, Steele } \\
\text { and Coyle,2013 } \\
\text { Stead et al,2012 }\end{array}$ & $\begin{array}{c}\text { Confident of diet's role in good health, participants } \\
\text { in this group eagerly recounted prostate-specific diet } \\
\text { discourses heard from support groups, public forums } \\
\text { and the media. Some asserted that specific foods and } \\
\text { supplements might suppress prostate cancer, and } \\
\text { potentially be more effective than traditional medicine. } \\
\text { Others began taking supplements and eating certain } \\
\text { vegetables because of hearing that they were somehow } \\
\text { beneficial for prostate cancer. This was often coupled } \\
\text { with reducing red-meat intake because they had heard } \\
\text { that excessive meat consumption was harmful for men } \\
\text { with prostate cancer. (Mróz, et al, 2010) }\end{array}$ & $\begin{array}{l}\text { One man snacked on walnuts and almonds believing } \\
\text { they were "more anti-cancer fighting" than peanuts } \\
\text { and "the more you can get into that, I think it's far } \\
\text { better for you than all the medicine they can ever } \\
\text { shove into you" (Mróz, et al, 2010). }\end{array}$ \\
\hline
\end{tabular}

to guide the search and ensure that only the most relevant studies were included in the review.

Following the initial database search, study tittles were searched by hand before being screened against the inclusion criteria, first on the basis of title and abstract (R1 - round one screening) and then using the full text (R2 - round two screening). All excluded papers and the reasons for their exclusion, were reviewed by a second researcher, although no changes were made following this review. Reference chaining was also conducted for included studies. A PRISMA flowchart containing details of the search and screening output is provided in Figure 2.

\section{Critical appraisal of material}

A single mixed methods critical appraisal tool was sought to evaluate the quality of all studies. This was deemed preferable to selecting different appraisal tools to rate the qualitative and quantitative research, in order to provide continuity of approach and a more robust comparative appraisal. The Mixed Methods Appraisal Tool (MMAT, [10]) was selected due to its applicability to diverse research methods.

The MMAT provides bespoke appraisal criteria for the different methodological approaches used within the research, namely: Qualitative, Quantitative randomised controlled trials, Quantitative non-randomised, Quantitative descriptive and Mixed methods. Criteria are presented as specific questions to which the researcher must select a response of 'Yes', 'No' or 'Can't tell' and record the rationale for their response. An overall quality appraisal score (of 0, 25, 50, 75 or 100\%) can then be generated for each paper (based on the weakest component), in addition to a descriptive summary.

\section{Synthesis}

Firstly, relevant data was extracted from each of the included studies. This was done by copying all text excerpts from the results sections of each study and recording the theme assigned to these excerpts by the author(s). When no authors' theme was provided, the researcher allocated their own theme based on their interpretation of the information.

Constant comparison of themes was then conducted by laying out all data excerpts in an open space and 'eyeballing' the theme titles, authors' commentary and participant quotes for similarities and differences. These were then re-grouped together under descriptive themes, before being reviewed by the second researcher.

Interpretive thematic analysis was then used to generate a set of analytic themes following constant comparison of the data. An explanation/rationale for these themes was also articulated, with the support of quotations and implications for findings drawn out [11].

\section{Results}

\section{Included studies}

Following the initial database search, a total of 1715 studies were returned. Following screening, 10 papers were included. With a further paper added following reference chaining. A synthesis of 11 papers was therefore conducted.

\section{Appraisal}

The included studies incorporated a range of research methods including qualitative $(n=4)$, quantitative descriptive $(n=3)$ and mixed methods $(n=4)$. Following independent quality appraisal, the scores assigned for all papers were reviewed by both researchers. There was high agreement between researchers regarding the quality appraisal scores assigned to 9 out of 11 studies, with variable quality out of a potential score of $100 \%$ identified $(n=1$ scored $0, n=2$ scored $25 \%, n=5$ scored $75 \%$, and $n=1$ scored $100 \%)$. Two papers were rated 1 mark differently by the researchers. Following detailed discussion of the rationale for these rating, both researchers felt that their scores were appropriate and hence a duel score of $50 / 75 \%$ was given to these papers $[12,13]$.

Overall, the modal score assigned across all studies was $75 \%$. Only one research paper [14] received the highest possible appraisal score of 100. A single research paper [15] also received the lowest possible appraisal score of $0 \%$, as it failed to meet any of the criteria specified (see Table 3 for individual quality appraisal scores).

\section{Synthesis of results}

The 11 included papers encompass research conducted in the UK $(n=3)$, America $(n=3)$, Canada $(n=2)$, Australia $(n=2)$ and New Zealand $(n=1)$. Studies were varied in their research design, with four using mixed methods, four using qualitative methods and 
three studies using quantitative descriptive research design $(n=3)$. Colorectal cancer survivors were the most frequent research participants across the 11 papers $(n=6)$, and the majority of studies $(n=8)$ included a combination of both male and female participants. The age range of participants (where known) was 20-84 years, with participant numbers ranging from 14-1128.

\section{Findings \& Implications For Practice}

\section{Constructs identified}

Following interpretive thematic analysis, five key themes were identified, along with10 sub themes (as illustrated within Figure 3). Each theme and sub-theme is presented within Table 4, along with a record of the papers where these constructs were present, and a first order construct to illustrate the theme.

\section{Advice \\ Satisfaction with advice}

With regards to satisfaction with advice, one study [16] comparing obese patients with healthy/low weight individuals identified a difference in perceptions of advice provision between these two groups. All obese study participants reported that they had not received dietary advice, however relatively even numbers in each participant group were provided with such advice. "Despite this 33\% of obese participants felt the dietary information received met their needs."

Another study [13] found different levels of satisfaction depending on the source/channel of information provision:

"...76\% of participants rated the programme overall as excellent, $100 \%$ rated the health coach as excellent, whilst $75 \%$ rated the handbook as excellent."

Excess of food related information does not appear to be a problem as none of the research cited having too much information as problematic, illustrated by the following Second order quotes:

"No patients felt they had received too much dietary information, whereas $61 \%$ felt they had received to little or far too little" [16].

"The majority of patients selected the prototype titled Food Borne Disease and Cancer Patients' because it contained the most information they needed....”[7].

\section{Advice seeking}

Information and advice was most commonly sought from the media, friends and family, health professionals and practitioners. Drivers for seeking information from these sources included:

"I had to ask to see a dietician cause I had put on a lot of weight. Um, and that was concerning me and causing me stress...” [20]

"......diarrhoea and flatulence were daily problems for which they sought simple practical dietary advice on foods to avoid" [12].

"The relief of the all clear combined with a health professional warning you could maybe have a wee bit of help with losing weight to make sure this doesn't happen again....” [17].

Studies therefore show that patients have a preference to receive more information as opposed to less, so that they are able to select the advice that best meets their needs and circumstance. Most commonly participants sought advice or information in order to lose weight, control bodily functioning or to reduce the threat of illness reoccurrence. This would suggest that advice given also needs to explicitly address these drivers.

\section{Contents of information}

\section{Coverage}

The majority of resources focused on provision of dietary/nutritional advice, with only one of the included research papers [7] focused on the provision of food safety information, concerning cooking, handling and storage. The content of food safety advice was explored in detail with recipients citing statistics and information on food borne illness, pathogens and symptoms to be the most helpful content in order to raise awareness of the risk and severity of food borne illness. Bespoke guides for Cancer patients were reported to be helpful, specifically those related to eating away from the home, safe cooking temperatures and safe food storage. In addition, information concerning foods best avoided and why was also met with positive feedback from participants.

Most Participants in this study recalled hearing recommendations to wash their hands frequently as well as washing fruits and vegetables prior to consumption. Recommendations widely accepted by cancer survivors [7] included avoidance of 'high risk' foods such as raw seafood, sprouts and unpasteurised juice and dairy products and not handling pets when preparing food.

\section{Conflicting messages}

Some participants reported dislike of the medical terminology used within food safety advice and difficulty pronouncing terms such as cryptosporidiosis and campylobacteriosis [7]. Participants instead reported a preference for text based information to be “... accurate, but not too technical.... Perhaps bullet point format...”. Participants receiving dietary advice and information cited confusion which appears to be routed in the specificity of information provided. Some examples include generic advice to "eat little and often" [12] which resulted in excess weight gain; broad information branded as 'useless' following a suggested trial and error approach to identify foods in response to problems experienced with bodily functions [17]. Dissonance of information was another source of confusion, as participants received information from practitioners which appeared to conflict with population recommendations, such as "the odd bit of vegetable that's not green in colour and maybe half the fruit a day" [12], as opposed to the standard guidance to eat five portions per day; and recommendations to consume fatty junk food following surgery, e.g. "...eat to get your strength back again and build up your weight again [...] drink full fat milk and take plenty of salt.." [12].

This highlights that cancer survivors are looking for prescriptive guidance that is easy to understand, along with contextual information to appreciate how and why the targeted recommendations provided to cancer survivors may appear to conflict with other 
generic health guidance they may be familiar with.

\section{Delivery of information}

\section{Timing}

Timing With regards to the timing of information and advice provision, the research was inconclusive as illustrated by the following excerpts:

".....soon after adenoma treatment, whilst recollections of the procedures were still bot" [17].

"..... would like to see at the end of treatment, some sort of survivorship audit where they're looking at your diet, your lifestyle, how much exercise your getting....." [12].

"... early after diagnosis and as soon as the first oncology appointment." [7].

One study delivering telephone counselling received extremely high rates of engagement which was attributed to the flexibility of delivery, at evenings and weekends, access to the counsellor via email and phone and regular appointment reminders [18].

This would suggest that cancer patients would value food related information as part of lifestyle advice and linked to the different phases experienced as a cancer survivor, from diagnosis to after treatment completion. This may help to build familiarity with the information and confidence to implement the recommended practices.

\section{Mode of delivery}

There were conflicting findings across the literature with regards to the preferred interpersonal source of dietary advice, as illustrated by the following excerpts:

"The most frequent source of dietary advice was a dietitian or friend/family member. No patients reported receiving dietary information from doctors or nurses." [16].

"Participants reported that the most common type of exposure to dieting information came from discussions with their physicians [19].

Moreover, positivity was expressed for the usefulness of cooking demonstrations, supplemented with recipe booklets and education [15].

In the context of food handling practices: "The patients preferred that physicians (five of six focus groups) or nurses (five of six focus groups) provide the information." [7]. Nutritionists were also cited as credible sources.

Secondary to interpersonal sources of information, were written brochures/booklets, pamphlets, or fact sheets [16, 12]. Fact sheets were also cited as the preferred format for receiving safe food handling advice [7]. Other less frequently cited modes of food related advice included:

- Media sources - stumbling across as opposed to actively seeking dietary information [19].
- Web sites/forums [7, 12].

- $\quad$ CD or downloadable PDF [16].

- Telephone helplines, such as Bowel Cancer UK [12].

- Support groups offering opportunity to talk to so called 'expert patients', who had first-hand experience of cancer treatment [12].

One study [7] identified that cancer patients were more likely to follow advice provided by nutritionists, physicians or nurses, perceived to be credible, as opposed to other sources such as the media, health coaches, herbalists and naturopathic doctors who were cited less frequently. Another highlighted the value added by different mediums, as exemplified within the following participant quote:

" [the thing] I found most useful was actually when I started coming to the bowel group in here... I think I was maybe due to get my stoma reversal and there was two people just had the reversal and they talked through it, I learned more from that than going on any internet or even speaking with the colorectal specialists" [12].

Whilst there is a broad range of formats and channels used to communicate food related information, those most commonly used and cited were documented takeaway information and/or interpersonal discussions with health professionals or practitioners. It is possible however that less formal interpersonal channels, such as forums and support groups may not be seen as information sources but rather sources of social support.

\section{Change}

\section{Behavioural drivers for change}

A range of factors were cited which motivated individuals to make food and lifestyle changes. These included "the constant threat of [illness] reoccurrence" [14], reaching a desired vision of self, either by returning to their pre-cancer lifestyle and body shape or creating a new healthy self-identity [12], and fear of foodborne illness or related death [7].

Information, advice and increasing personal knowledge were often cited as instigators for change, leading to one or more of the above prompts to change. Consequently, it seems as though availability and provision of food related information plays a pivotal role in raising risk awareness, self-reflection and subsequently, facilitating healthy lifestyle change.

\section{Willingness to change}

Broadly, the data indicates a general willingness to make, or consider making, changes to their food related behaviour and lifestyle, particularly following some form of information or advice $[16,15,18]$ as illustrated by the following excerpt:

"... dieting was reported by $49.5 \%$ of those who did and only $29.7 \%$ of those
who did not discuss dieting with their physicians" [19].

"...participants who received the Healthy Options module $(n=33)$, a statistically significant increase in daily consumption of fruits and vegetables was 
found, from 3.8 to 4.6 daily servings ( $p=0.02$ )" [18].

It would seem that information or advice provision serves as a prompt to consider or initiate nutritional behaviour change. The variance in format, channel and content however make it difficult for this review to determine the specific format which is most beneficial for change amongst this at risk population.

\section{Bartiers to implementing change}

Some recommendations were deemed to be 'common sense', such as not handling pets whilst preparing food [7], or using a thermometer when cooking meat: "I have cooked long enough to know what is done or not" [7]. Consequently, participants were reluctant to implement such recommendations.

Lack of concern was identified as a barrier to implementing recommendations, both with regards to food safety [7] and making lifestyle changes [17]. Personal preference for consuming unpasteurised foods, inconvenience of recommended practices and lack of knowledge surrounding 'dangerous' foods were all cited as factors contributing to high risk food consumption and handling behaviours [7].

Advice on lifestyle change was also perceived to lack consistency, making it difficult to follow: "If you read the newspapers you realise that whatever you do is bad for you?" [17].

This would suggest that food related advice in future should seek to address common barriers to implementation, namely: justifying the value of advice that may be considered 'common sense', conveying risk severity, promoting a consistent message and highlighting substitutions for high risk foods and handling practices that are both convenient and appealing.

\section{Beliefs}

\section{Link between diet \& cancer}

Cancer survivors were varied in their perception of the relationship between general health and the onset and survival of cancer, with three broad schools of thought emerging across the research as follows:

a) Positive link between diet and cancer outcomes

Some participants enthusiastically described lifestyle changes that they had made in order to improve cancer outcomes, such as reducing consumption of red meat and increasing consumption of walnuts and almonds for their cancer fighting properties. One individual spoke about implementing a range of recommendations to support optimum immune system functioning, stating “... if your immune system is in tip top shape then you can beat cancer just like you can heal from anything else" [14].

b) Negative/no link between diet and cancer outcomes

Some individuals remained unconvinced by the evidence linking diet with cancer and consequently, showed resistance to making lifestyle change. Some first order quotes exemplifying this include:

"There's no data on prostate cancer, there's absolutely no data reliable infor- mation about what works and what doesn't' [14].

"...I think that so called cures occur occasionally for reasons, which people don't really understand, and food I don't think has much to do with it' [14].

One researcher also highlighted scepticism over delivering lifestyle advice to cancer patients as this presented a convenient interaction opportunity and "just because it's the done thing", regardless of whether such individuals specifically would benefit from lifestyle advice [17].

Other individuals displayed resentment towards the link between diet and cancer, feeling as though they were being blamed for their illness. Instead they attributed stress as a major cause or contributor to their diagnosis [12]. Moreover, a small number of individuals cited the opinion and experience that lifestyle change may actually increase cancer risk and upset bodily functions. Consequently, a need for bespoke tailored advice under regular review was sought by such individuals [12].

c) Diet as a preventative measure.

Lack of understanding concerning causes and prevention of cancer, were exacerbated by the fact that "participants were not encouraged to think about prevention during the treatment process..." [17].

Some participants perceived their diet to be healthy prior to cancer onset and hence, no major improvements were deemed necessary. However, such individuals still reported intensifying efforts and supplementing certain foods [17].

Furthermore, it would seem that some cancer survivors view the progress of their illness as an indicator of their overall health, rather than their health as a risk or indicator of cancer onset or remission. 'All clear' messages communicated by health professionals were seen to reinforce current lifestyle behaviours, thus fostering resistance to change. For example, "To me, that tells me that I'm all clear..... so why do I need to change my diet?" [17].

The studies highlight the need to contextualise food related advice with the evidence base for effectiveness and the benefits to both cancer survivorship and general health. Moreover, it illustrates the challenge of encouraging preventative food related health behaviours at a time when individuals already see themselves as fit and healthy.

\section{Discussion}

\section{Summary of key findings}

Following a systematic MSR of literature in this field ( $\mathrm{n}=11$ studies), it can be said that there is a preference for receiving more information as opposed to less, with survivors primarily seeking prescriptive guidance that is easy to understand, via a broad range of channels, most commonly discussions with health professionals/practitioners or written takeaway information. Food related information was valued as part of broader lifestyle advice, in particular when linked to the different phases experienced, from diagnosis to after treatment completion. Finally, information or advice provision appears to serve as a prompt to consider or initiate nutritional behaviour change, with cancer diagnosis often re- 
ferred to as a teachable moment. However, encouraging preventative food related health behaviours at a time when individuals already see themselves and fit and healthy, following remission, is acknowledged to be challenging.

\section{Strengths and limitations}

Due to the advances in Cancer research and changes in the channels/technology used to convey health communications, the researcher chose to limit searches to include only material published within the last six years. This may present a limitation of the current review however, the present review could be supplemented by a review of earlier literature if this is deemed to be useful and relevant to current practice. Furthermore, future studies may wish to incorporate grey literature sources and contact the authors of all included studies to ensure that a fully comprehensive review of literature on the subject has been reviewed.

The quality of the review will be dependent on the quality of the included studies, which in this case was variable. From a pool of 11 relevant studies identified, four studies [16, 14, 15, 19] specially focused on diet, one paper [7] focused on safe food handling practices and five papers $[20,12,18,17,13,21]$ explored food related information in the context of wider health services and lifestyle interventions. Understanding cancer patients' experiences of food related information was not an explicit research objective amongst any of the papers and hence, there was also considerable variation in the research aims and methods employed across the literature identified.

A core strength of this systematic mixed studies review (MSR) is the incorporation of qualitative, quantitative and mixed method studies, enabling synthesis of different types of evidence, and concomitant quality appraisal using the MMAT [22].

\section{Recommendations}

The following recommendations for policy and practice can be drawn from present review of current literature.

1. Raising perceptions of risk susceptibility seems necessary prior to increasing awareness and perceived efficacy of safe and healthy food related behaviours.

2. Increasing the consistency of nutritional messaging through a diverse range of channels would seem beneficial in order to increase consumer confidence to implement.

3. Contextualising information relative to the consumer journey, from diagnosis and as a cancer patient though to survivorship and back into normal life.

4. Increase consumer awareness of the benefits and risks to different food related behaviours such that they are better able to make informed food handling and consumption decisions.

The apparent lack of relevant research indicates a lack of evidence on which to base definitive decisions for future practice however. In particular, with regards to food safety messages. Further research in this area is therefore required in order to better inform this population group and meet their needs with respect to both nutrition and food safety information.

\section{Conclusion}

To conclude, this review sought to better understand Cancer survivors' perceptions of food related information, with a view to enhancing the effectiveness of such information in future. Based on the findings, survivors appear to seek simple, relevant and prescriptive guidance via practitioners and paper based channels. If cancer survivorship is to be capitalised as a teachable moment with regards to improving food safety and nutrition, further empirical research is necessary to understand and enhance food related behaviours amongst cancer survivors, an acknowledged 'at risk' group.

\section{References}

[1]. Cancer Research UK (2015) Cancer Statistics for the UK, retrieved August 2015 from http://www.cancerresearchuk.org/health-professional/cancerstatistics.

[2]. Cancer Research UK (2014) Data Table: Cancer cases and deaths in the UK, retrieved August, 2015 from http://publications.cancerresearchuk.org/ cancerstats/statsincidence/dtcasesdeaths.html, Accessed.

[3]. LiveStrong Foundation (2015) Finding and Evaluating Cancer Information, retrieved August, 2015 from http://www.livestrong.org/we-can-help/justdiagnosed/finding-and-evaluating-cancer-information/

[4]. Greenstreet BermanLtd (2011) Evidence review of food safety behaviours in the home. Food Standards Agency. http://www.food.gov.uk/sites/default/ files/700-1-1185_X04009_FINAL.pdf

[5]. Food Standards Agency (2010) Science and Evidence Strategy 2010-2015. Retrieved August, 2015 from http://tna.europarchive.org/20110912091909/ http://www.food.gov.uk/multimedia/pdfs/publication/sciencestrat0210.pdf

[6]. Hof H, Nichterlein T, Kretschmar M (1997) Management of listeriosis. Clin Microbiol Rev 10(2): 345-357.

[7]. Medeiros LC, Chen G, Hillers VN, Kendall PA (2008) Discovery and development of educational strategies to encourage safe food handling behaviours in cancer patients. J Food Prot 71(8): 1666-1673.

[8]. Kendall P, Medeiros LC, Hilliers V, Chen G, DiMascola S (2003) Food handling behaviors of special importance for pregnant women, infants and young children, the elderly, and immunocompromised people. J Am Diet Assoc 103(12): 1646-1649.

[9]. Cooke A, Smith D, Booth A (2012) Beyond PICO: the SPIDER tool for qualitative evidence synthesis. Qual Health Res 22(10): 1435-1443.

[10]. Pluye P, Robert E, Cargo M, Bartlett G, O'Cathain A, et al. (2011) Proposal: A mixed methods appraisal tool for systematic mixed studies reviews. Retrieved on [July 2015] from http://mixedmethodsappraisaltoolpublic.pbworks.com/w/page/24607821/FrontPage

[11]. Braun V, Clarke V (2006) Using thematic analysis in psychology. Qualitative Research in Psychology 3(2): 77-101.

[12]. Anderson AS, Steele R, Coyle J (2013) Lifestyle issues for colorectal cancer survivors - Perceived needs, beliefs and opportunities. Support Care Cancer 21(1): 35-42.

[13]. Hawkes A, Gollschewski S, Lynch B, Chambers S (2009) A telephone-delivered lifestyle intervention for colorectal cancer survivors 'CanChange': A pilot study. Psychooncology 18(4): 449-455.

[14]. Mróz L, Chapman G, Oliffe J, Bottorff J (2010) Prostate cancer, masculinity and food. Rationales for perceived diet change. Appetite 55(3): 398-406.

[15]. Urowitz S, Chiu W, Cockburn M, Dunlop B, Fierini D, et al. (2012) Building Recipes and Understanding Nutrition for Cancer-survivor Health (BRUNCH). J Nutr Educ Behav 44(4): 384-386.

[16]. Pullar J, Chisholm A, Jackson C (2012) Dietary information for colorectal cancer survivors: an unmet need. N Z Med J 125(1356): 27-37.

[17]. Stead M, Caswell S, Craigie A, Eadie D, Anderson A, et al. (2012) Understanding the potential and challenges of adenoma treatment as a prevention opportunity: insights from the BeWEL formative study. Prev Med 54(1): 97-103.

[18]. Garrett K, Okuyama S, Jones W, Barnes D, Tran Z, et al. (2013) Bridging the transition from cancer patient to survivor: Pilot study results of the Cancer Survivor Telephone Education and Personal Support (C-STEPS) program. Patient Educ Couns 92(2): 266-272.

[19]. Tan AS, Mello S, Hornik RC (2012) A longitudinal study on engagement with dieting information as a predictor of dieting behavior among adults 
diagnosed with cancer. Patient Educ Couns 88(2): 305-310.

[20]. Lawler S, Spathonis K, Masters J, Adams J, Eakin E (2011) Follow-up care after breast cancer treatment: experiences and perceptions of service provision and provider interactions in rural Australian women. Support Care Cancer 19(12): 1975-1982.

[21]. Anderson AS, Caswell S, Wells M, Steele RJ, Macaskill S (2010) "It makes you feel so full of life" LiveWell, a feasibility study of a personalised lifestyle programme for colorectal cancer survivors. Support Cancer Care 18(4): 409415.

[22]. Pace R, Pluye P, Bartlett G, Macaulay A, Salsberg J, et al. (2012) Testing the reliability and efficiency of the pilot mixed methods appraisal tool (MMAT) for systematic mixed studies review. Int J Nurs Stud 49(1): 47-53.
Special Issue on

"Dietary Patterns and Health Risks"

Theme Edited by:

Shun-Wan Chan, The Hong Kong Polytechnic University, Hong Kong.

E-mail: sw.chan@polyu.edu.hk 